\title{
Expression of COX-2, HMGB-1 and CD68 in lung tissue in sheep fibrinous bronchopneumonia")
}

\author{
ORHAN YAVUZ, GÜNGÖR ÇAĞDAŞ DINÇEL*
}

\begin{abstract}
Department of Pathology, Faculty of Veterinary Medicine, *Laboratory and Veterinary Assistance Services, Eskil Vocational School, Aksaray University, 68100, Aksaray, Turkey
\end{abstract}

\section{Yavuz O., Dinçel G. Ç.}

\section{Expression of COX-2, HMGB-1 and CD68 in lung tissue in sheep fibrinous bronchopneumonia}

\section{Summary}

This study aimed to determine the expression of some cytokines, such as cyclooxygenase-2 (COX-2), High Mobility Group Box-1 (HMGB-1) and CD68, in the lung tissue of sheep with fibrinous bronchopneumonia by immunohistochemical methods. Forty sheep which had suffered from respiratory problems were brought for necropsy to the Faculty of Veterinary Medicine, Department of Pathology, Aksaray University, between November 2014 and December 2017. After necropsy, lung tissues grossly diagnosed with fibrinous bronchopneumonia were processed histologically, and stained histopathologically and immunohistochemically. Bacteriological culture was also applied to the lung tissues to isolate the agents. In histopathological examinations, congestion, red consolidation and grey consolidation stages were detected in the lung tissues. In such cases, we observed fibrin masses accumulated in some alveolar lumens, as well as inflammatory cell infiltrations of various extent in alveolar and bronchiolar lumens. In the interalveolar septum, a thickening was observed due to a fibrin mass and thrombotic vessels. Immunohistochemically, it was determined that COX-2 and HMGB-1 cytokines showed positive reactions, especially in bronchial, bronchiolar and alveolar epithelia, as well as goblet cells and macrophages. CD68 was found to be expressed in alveolar macrophages. COX-2 and HMGB-1, which have been implicated in the inflammatory response, were also shown to be expressed in fibrinous bronchopneumonia in sheep for the first time. Thus, these cytokines are thought to play a role in the pathogenesis of the disease. Moreover, their increased expression suggests that it may be helpful in the diagnosis of the disease.

Keywords: CD68, COX-2, HMGB-1, immunohistochemistry, sheep

Fibrinous bronchopneumonia (FBPN) is a lung inflammation characterized by the presence of an abundant fibrin mass in the inflammatory exudate. It can be found in domestic animals, such as cattle, sheep, goats, horses, dogs and pigs. Bacterial agents, such as Pasteurella spp., Mannheimia spp. and Mycoplasma spp. are known to cause FBPN in sheep (21). Although pneumonia is histologically known as the inflammation of the lung alveoli, lung inflammation is termed pneumonia as a general concept. With regard to the pathogenesis, morphology and the spread of pneumonia in the lung, bronchopneumonia is divided into 3 subheadings as catarrhal-purulent bronchopneumonia, FBPN and aspiration pneumonia. Grossly, at least one of the cranial lobes of the lungs appears as red, brown or grayish in colour and consolidated. During the development of pneumonia, there are four consecutive periods distinguished by the appearance of the

This study was funded by Aksaray University Scientific Research Committee (ASÜBAP, Project No. 2018-024). lungs and the characteristics of the exudate: congestion, red consolidation, gray consolidation and lysis $(6,23)$.

Prostaglandins, which are derived from arachidonic acid, are potent inflammatory mediators that play a role in physiological processes in the lungs, such as bronchoconstriction, vasodilation and mucus secretion. Prostaglandins also have a synergistic effect with some other mediators in an increase of transvascular hydrostatic pressure and microvascular permeability. Prostaglandins are synthesized from arachidonic acid by two cyclooxygenase (COX) isoforms. The first, COX-1, facilitates the synthesis of prostaglandins involved in homeostatic functions, while COX-2 is an inducible enzyme that is predominantly expressed at inflammatory sites. COX-2 is expressed by the presence of lipopolysaccharides together with inflammatory cytokines, such as interleukin-1 (IL-1) or tumor necrosis factor (TNF) alpha (5). High-mobility group box 1 protein (HMGB-1), which was previously believed to affect DNA transcription, has in recent years been 
recognized as an important cytokine in the inflammatory immune response (22). Cluster of differentiation 68 (CD68) is a membrane protein found in lysosomal membranes and cell surfaces of macrophages in tissues. CD68 is closely related to the family of lysosomalrelated mucin-like membrane proteins (18).

In this study, we sought to determine the expression of some cytokines, such as COX-2, HMGB-1 and CD68, in sheep FBPNs by immunohistochemical methods. The effects of these cytokines released in the early stages of inflammation were investigated in acute FBPN disease in sheep. Thus, we also investigated which tissues played a more active role in the pathogenesis of inflammation.

\section{Material and methods}

Material. Between November 2014 and December 2017, a total of 208 sheep were brought to the Department of Pathology of the Faculty of Veterinary Medicine of Aksaray University for routine necropsy. After necropsies, it was found that 40 sheep died of FBPN, and the rest died of other causes (Fig. 1). The forty sheep that died of FBPN (at the age of 3 to 18 months) were included in the study. For the control, lung tissues of 10 healthy sheep were obtained from a slaughterhouse.

Bacteria isolation. Samples taken from the lungs affected by pneumonia were inoculated onto mycoplasma agar for Mycoplasma spp. isolation and incubated at $37^{\circ} \mathrm{C}$ for 14 days in an aerobic medium. The same samples were inoculated onto blood agar and MacConkey agar for Pasteurella spp. and Mannheimia spp. isolation and incubated at $37^{\circ} \mathrm{C}$ for 48 hours in an aerobic medium (27).

Histopathological method. Following necropsy, samples of lung tissues were placed in a $10 \%$ formalin solution. After fixation, the tissues were treated with alcohol, xylene and paraffin wax. Sections were cut at $5 \mu \mathrm{m}$ with a microtome and mounted on slides. The sections were immersed three times for $5 \mathrm{~min}$ each in xylene and then in $96 \%, 90 \%$, $80 \%, 70 \%$ and $50 \%$ alcohol for rehydration. They were stained with hematoxylin and eosin.

Immunohistochemical method. The method applied by Dinçel (9) was used for immunohistochemical examinations. For this purpose, $5 \mu \mathrm{m}$ thick paraffin sections were placed on positively charged slides. The sections were dried in an oven at $60^{\circ} \mathrm{C}$ for 15 minutes. After deparaffinization, the sections were boiled for $20 \mathrm{~min}$ in citrate buffer solution for antigen retrieval. To block endogenous peroxidase activity, $3 \% \mathrm{H}_{2} \mathrm{O}_{2}$ was dropped onto slides at room temperature for 7 minutes. After this process, the block solution was added for 5 minutes, and the primary antibodies were incubated for 2 hours [Anti-COX-2 antibody (Santa Cruz Biotechnology, inc. sc-19999), Anti-HMGB-1 antibody (Santa Cruz Biotechnology, inc. Sc-135809) and Anti-CD68 antibody (Santa Cruz Biotechnology, inc. sc-514937)]. Each immunostaining by primary antibodies was done on separate slides. At the end of incubation, a biotinylated secondary antibody and streptavidin solution were added at 15-minute intervals. The sections were finally stained

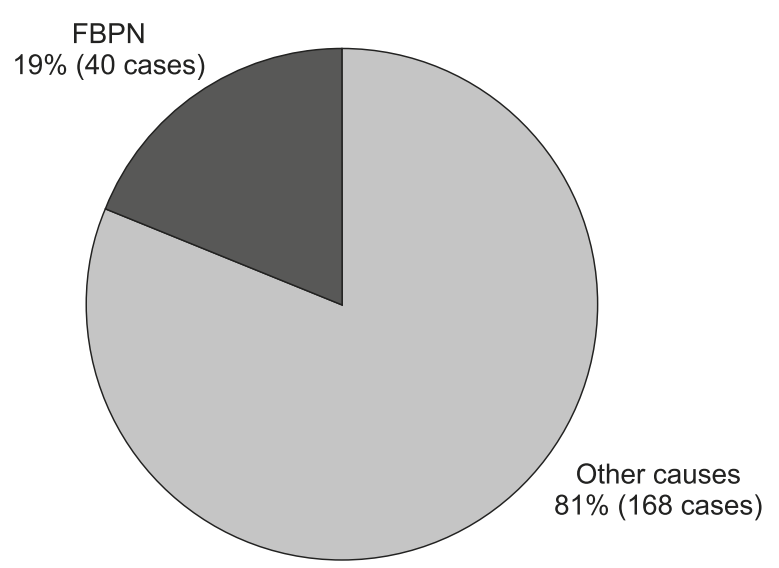

Fig. 1. Incidence of FBPNs between November 2014 and December 2017

with aminoethyl carbazole (AEC) and hematoxylin. The sections were covered with a coverslip and examined under a light microscope (Olympus BX51, Tokyo, Japan). After each step, the sections were washed three times for $5 \mathrm{~min}$ with phosphate buffer saline (PBS). However, washing was not performed after just blocking step and directly primary antibody incubation was started.

The negative and positive control slides were also stained according to the same procedure. However, PBS was used instead of the primary antibody during the negative control slides staining. The urinary bladder, esophagus and spleen tissue of sheep were stained as positive control for COX-2, HMGB-1 and CD68, respectively. Epithelial immunopositive reactions were evaluated as positive for $\mathrm{COX}-2$ and HMGB-1. On the other hand, randomly distributed staining was assumed as positive for CD68 in spleen tissue.

Immunohistochemical scoring. In the immunohistochemical scoring of the sections, bronchial epithelia, bronchiolar epithelia, alveolar epithelia, inflammatory cell infiltrations and glands were examined semi-quantitatively. To avoid observer bias, a blinded investigator examined all of the sections again. Immunohistochemical staining scores were classified as low, moderate and high expression according to the following criteria:

(-) If no immunopositive reaction was observed.

$(+)$ Low. If immunopositive reactions showed poor staining and were limited to one region of the slide.

$(++)$ Moderate. If immunopositive reactions were prominent and multifocally distributed in the slide.

$(+++)$ High. If immunopositive reactions were prominent and diffusely distributed in the slide.

Statistical analysis. The statistical results of immunohistochemical staining were analyzed by the IBM SPSS ${ }^{\circledR}$ Statistics V22 program using One-Way ANOVA and Tukey's test. Data were statistically described in terms of mean and standard deviation (mean $\pm \mathrm{SD}$ ) for immunohistochemical scoring. Statements on statistical significance are based on a $\mathrm{P}$ value $<0.05$.

Ethical considerations. The study was performed according to internal regulations promulgated by the Ministry of Agriculture and Forestry of the Republic of Turkey. It was also conducted in compliance with universal ethical standards. 


\section{Results and discussion}

Microbiological results. The microbiological results are given in Figure 2. According to these results, Mycoplasma spp. were isolated in 11 cases, Pasteurella multocida in 4 cases, and Mannheimia haemolytica in 25 cases.

Histopathological results. In histopathological examinations, congestion, red hepatization (consolidation) and grey hepatization stages were detected in the lung tissues of the sheep (Fig. 3A). In the red consolidation period, a fibrin mass and mononuclear cell infiltrations were observed in the alveolar lumens. Additionally, hyperemic vessels of alveolar capillaries were noted (Fig. 3B). Moreover, in the interlobular septum, a thickening was observed due to a fibrin mass, edema and thrombotic vessels (Fig. 3C). In 29 cases, the so-called "oat cells" were found, which are typical of pneumonic pasteurellosis (Fig. 3D).

Immunohistochemical results. Immunohistochemical staining scores are summarized in Tab. 1 and

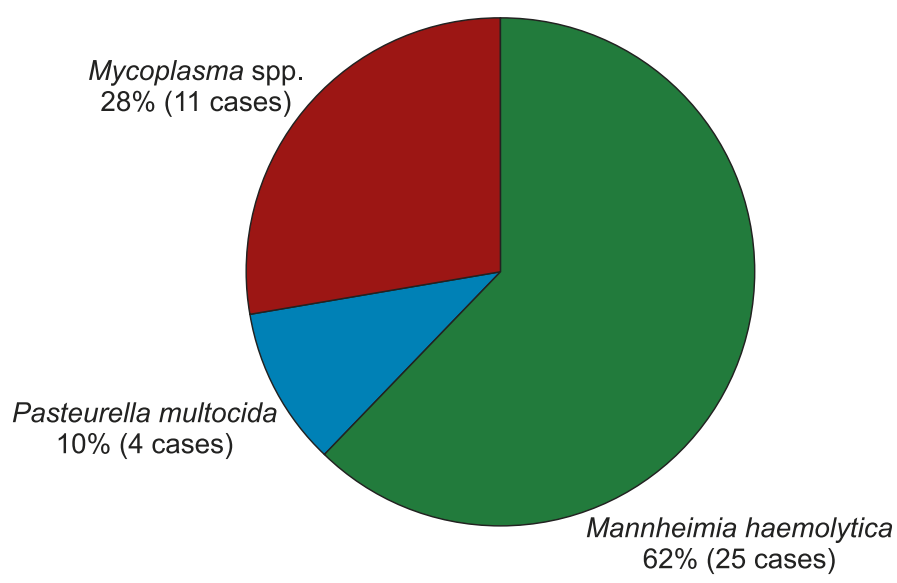

Fig. 2. The results of bacteria isolation

Fig. 4. According to the immunostaining results, $\mathrm{COX}$ 2 was positive in the bronchiole, bronchi, inflammatory cells and alveoli epithelia (Fig. 5A-B). The positive reactions observed were mostly intracytoplasmic (Fig. 5C). In addition, bronchiolar immunopositive reactions
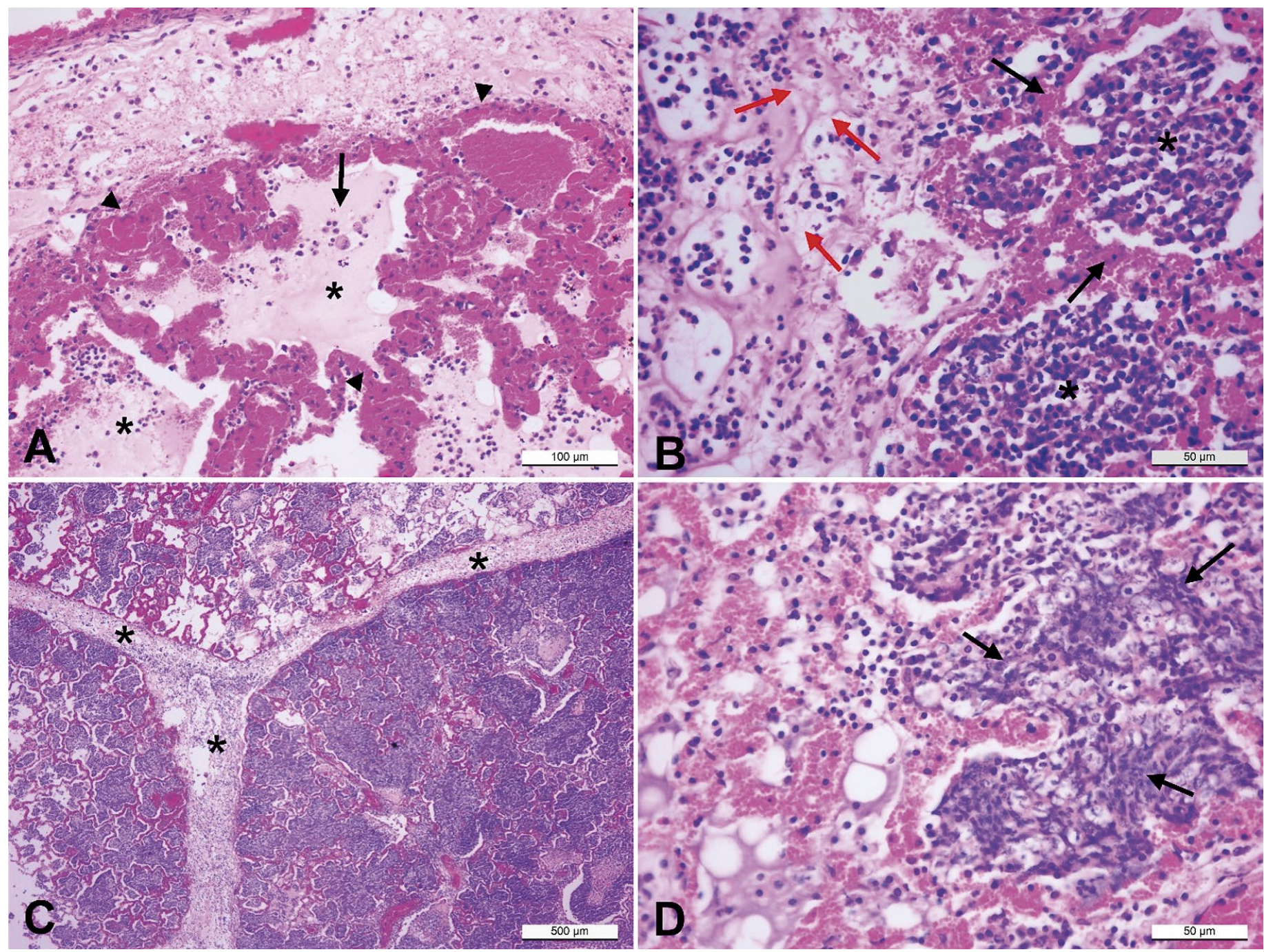

Fig. 3. Histopathological staining of affected lungs. A. Congestion stage. Hyperemia in the capillary vessels around the alveoli (arrowheads), a small number of cell infiltrations in the lumen of the alveoli (arrow), and edema in the lumen of the alveoli (asterisks). HE. B. Red hepatization stage. Hyperemia in the capillary vessels around the alveoli (black arrows), a large number of cell infiltrations (asterisks) and fibrinous mass in the alveoli (red arrows). HE. C. Thickening of the interlobular septum due to fibrinous mass, edema and inflammatory cell accumulation (asterisks). HE. D. Spindle-shaped oat cells. Oat cells, characteristic of pneumonic pasteurellosis, are thought to be a result of degeneration of neutrophils and monocytes (arrows). HE 
were statistically different from those in other structures, such as the bronchi, alveoli or glands ( $P$ value $<0.05)$. Similarly, HMGB-1 immunopositive staining was seen in the bronchi, bronchiole, alveoli, inflammatory cells and glands (Fig. 6A-C). However, the most severe reactions were obtained from the gland and bronchi epithelia, and positive immunostaining findings for these structures were statistically similar ( $\mathrm{P}$ value $>0.05)$. CD68-positive reactions were also
Tab. 1. Immunohistochemical staining scoring results of the study $(n=40)$

\begin{tabular}{|l|c|c|c|}
\hline Histological structures & COX-2 & HMGB-1 & CD68 \\
\hline Bronchus & $1.775 \pm 0.861^{\mathrm{bc}}$ & $2.075 \pm 0.828^{\mathrm{b}}$ & $0.150 \pm 0.361^{\mathrm{a}}$ \\
Bronchulus & $1.950 \pm 0.814^{\mathrm{c}}$ & $1.550 \pm 0.814^{\mathrm{a}}$ & $0.125 \pm 0.333^{\mathrm{a}}$ \\
Alveoli & $1.400 \pm 0.777^{\mathrm{b}}$ & $1.475 \pm 0.715^{\mathrm{a}}$ & $0.075 \pm 0.266^{\mathrm{a}}$ \\
Inflammatory Cells & $1.625 \pm 0.898^{\mathrm{bc}}$ & $1.450 \pm 0.845^{\mathrm{a}}$ & $1.600 \pm 0.900^{\mathrm{b}}$ \\
\hline Glands & $0.650 \pm 0.699^{\mathrm{a}}$ & $2.375 \pm 0.627^{\mathrm{b}}$ & $0.050 \pm 0.200^{\mathrm{a}}$ \\
\hline
\end{tabular}

Explanation: $a, b, c$ means with different superscript letters differ significantly within columns at $\mathrm{p} \leq 0.05$

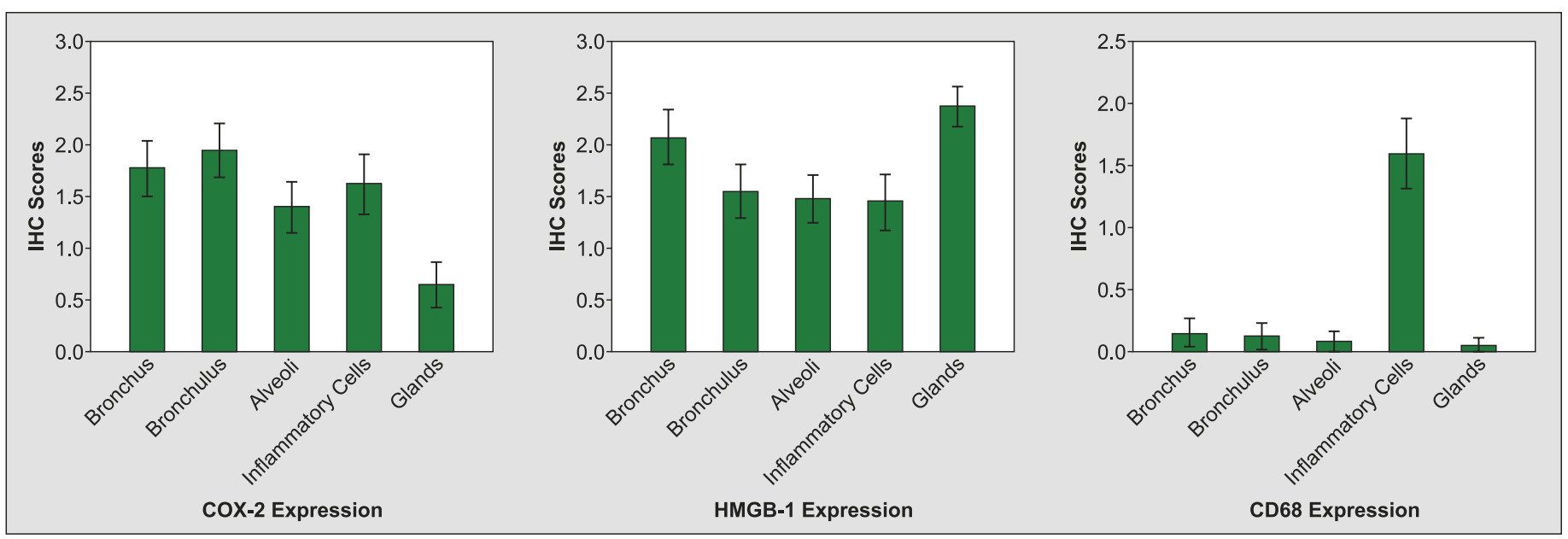

Fig. 4. Immunopositive staining scores. COX-2, HMGB-1 and CD68 expression

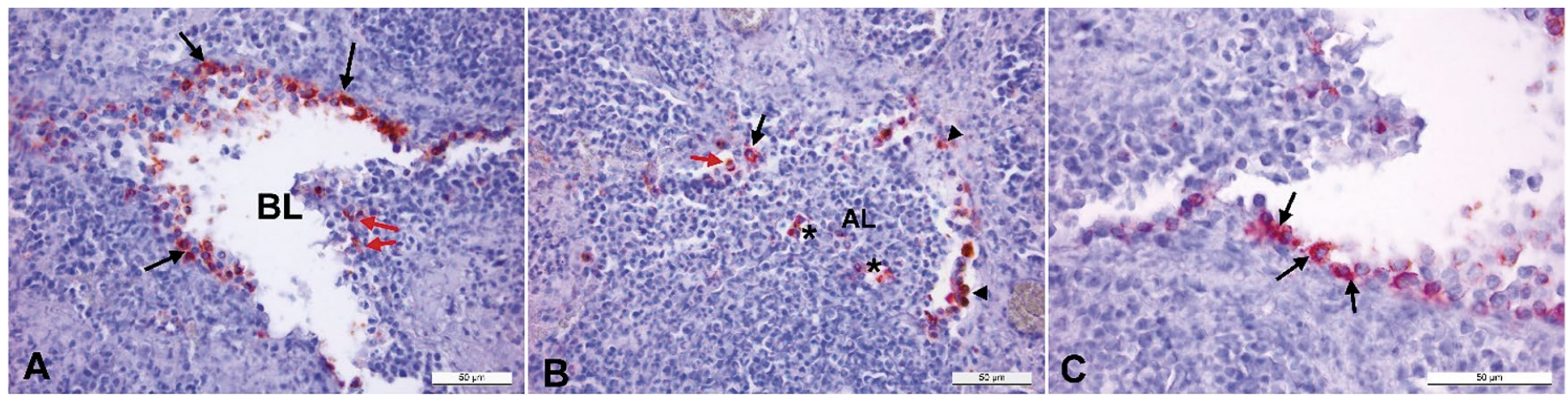

Fig. 5. Anti-COX-2 antibody immunopositive staining. A. Positive staining in the bronchiole epithelia (black arrows) and desquamated epithelia (red arrows) in the lumen of the bronchiole (BL). AEC. B. Positive staining in the alveoli epithelia (arrowheads), desquamated epithelia (asterisks) in the lumen of the alveoli (AL), a neutrophil granulocyte (red arrow) and a macrophage (black arrow). AEC. C. High magnification of the positive cells, mostly intra-cytoplasmic immunostaining (arrows). AEC

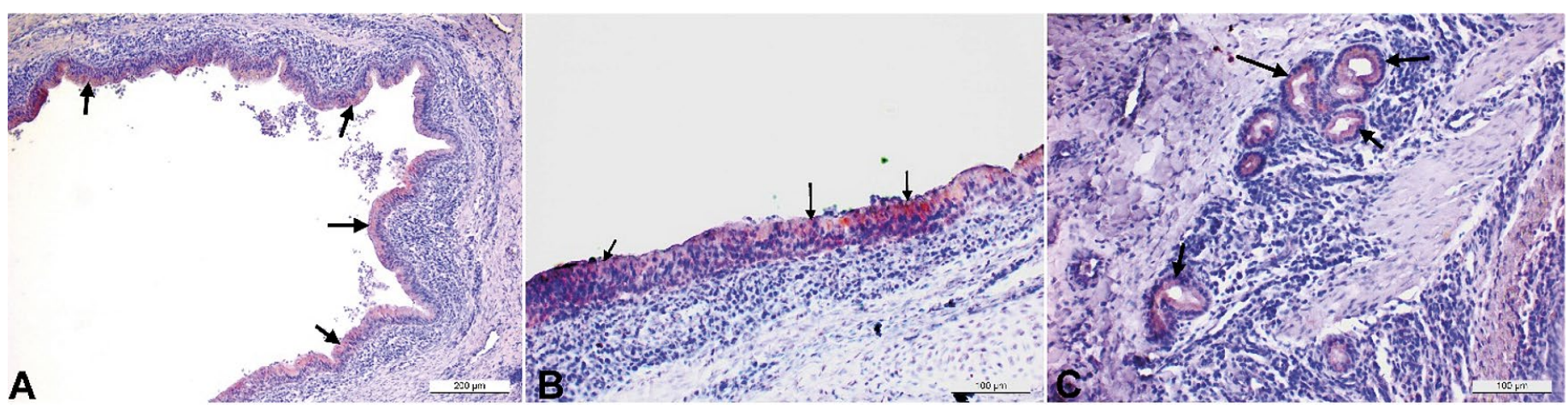

Fig. 6. Anti-HMGB-1 antibody immunopositive staining. A. Positive staining in the bronchi epithelia (arrows). AEC. B. High magnification of the positive immunostaining in the epithelia of the bronchi (arrows). AEC. C. Positive reactions in the gland epithelial cells (arrows). AEC 


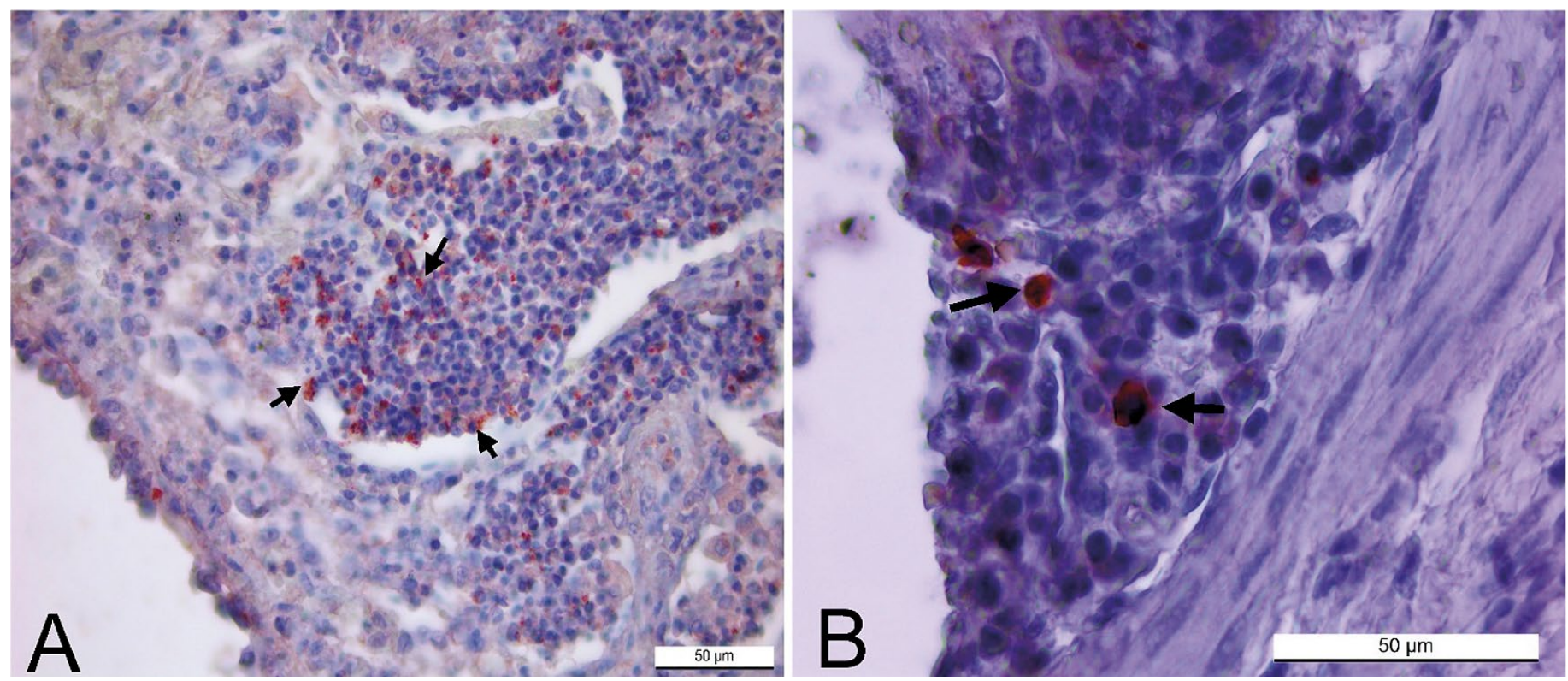

Fig. 7. Anti-CD68 antibody immunopositive staining. A. Positive staining in alveolar lumens in a free form (arrows). AEC. B. High magnification of immunopositive macrophages in peribronchiolar inflammatory cells (arrows). AEC

seen in alveolar macrophages and in a free-form manner in the alveolar lumens (Fig. 7A-B).

Pneumonia is one of the most common diseases on livestock farms around the world, causing considerable mortality among animals kept there. One study reported the proportion of farm animal deaths due to respiratory system diseases to be between 15\% and 20\% (7). In another study on sheep, this rate was reported as $28 \%$ (8). Elsewhere, Oruç (24) found this rate to be $26.72 \%$. In the present study, this proportion was $19 \%$. FBPNs are considered to be a more severe type of pneumonia than catarrhal bronchopneumonia because of their lobar distribution in the lungs (21). In addition, FBPN agents, such as Pasteurella spp. and Mannheimia spp., cause septicemia and further exacerbation of infection in young animals. In this study, COX-2, HMGB-1 and CD68 were immunohistochemically shown to be expressed in lung tissues of sheep affected by FBPN. These findings were described here for the first time and compared with histopathological results.

To date, the presence and levels of COX-2 have been investigated in cancer and inflammatory reactions in the lungs of many species $(4,17,19,20)$. In this study, the expression of COX-2 was examined in the lungs of sheep with fibrin bronchopneumonia. Cho and Chae (5) stated that COX-2 plays a role in the pathophysiology of pleuropneumonia in swine. In the same study, they observed positive reactions in the bronchus, bronchioles and alveolar type I epithelia, which were most commonly expressed from macrophages and neutrophil granulocytes. On the other hand, it was reported in another study that, in streptococcal pneumonia, immunopositive reactions were obtained in macrophages, vascular endothelial cells and type II pneumocytes (28). In the present study, COX-2 was predominantly seen in the epithelia of bronchus, bronchulus and inflammatory cell infiltrations. In addition to inflammatory cells, bronchial and bronchiolar epithelial cells may play a role in $\mathrm{COX}-2$ expression in FBPNs.

HMGB-1, which is an important proinflammatory cytokine, has been reported to be associated with a decreased inflammatory response, tissue damage and death of animals in the case of low expression (15). In one study, it was found that HMGB-1 plays a role as a late-acting inflammatory mediator in septicemia and endotoxemia (29). At the same time, unlike proinflammatory agents, such as TNF and ILs, it was determined that HMGB-1 is expressed in inflammatory sites for a longer period of time (23). Ding et al. (10) found increased levels of HMGB-1 in the peripheral blood of children with Mycoplasma pneumonia infection. Similarly, Ito et al. (13) reported that the serum HMGB-1 concentration was increased in patients with severe pneumonia. Achouiti et al. (1) stated that HMGB-1 caused edema in pneumonia induced by Staphylococcus aureus. Although there are few studies on the location of HMGB-1 in pneumonia by immunohistochemical methods, one study notes that HMGB-1 in human lungs with pulmonary fibrosis is expressed in macrophages, inflammatory cells and lung epithelial cells (11). In the present study, positive immunoreactivity was commonly observed in the bronchial and gland epithelia. In addition, the positive staining of bronchial and alveolar epithelia, as well as inflammatory cell infiltrations, suggest that, in FBPNs, HMGB-1 is expressed in the lungs.

CD68 was found only in macrophages and freely found in areas of inflammatory cell accumulations. Previous studies have demonstrated that leukotoxins produced by Mannheimia cause cytolysis in neutrophils and macrophages $(14,26)$. Thus, it was thought 
that CD68-positive immunohistological staining was obtained not only in macrophages but also freely in inflammatory areas.

Ackermann and Brogden (2) state that the brochus, bronchulus, alveoli and glands perform many tasks, such as antimicrobial activity, inflammatory response and detoxification of toxins. In previous studies, Mannheimia, Pasteurella and Mycoplasma agents were most commonly detected by immunohistochemical examinations in bronchial, bronchiolar, alveolar, epithelial and inflammatory cells $(3,8,16,24,27,30)$. In this study, the expression of COX-2, HMGB-1 and CD68 was found in the above-mentioned structures by immunohistochemical analysis. Accordingly, agents such as Mannheimia and Pasteurella stimulated the release of COX-2, HMGB-1 and CD68 in lung tissue.

In histopathological examinations, shuttle-shaped oat cells are seen in both Pasteurella- and Mannheimiainduced FBPN cases. It has been noted that oat cells appear due to the effect of bacteria endotoxins on leukocytes (12). In this study, oat cells were found microscopically in 29 cases. In microbiological examinations, Mannheimia was isolated in four cases, and Pasteurella in 25 cases. Thus, both methods confirmed the diagnostic validity of each other. However, although the expression of COX-2, HMGB-1 and CD68 was observed in inflammatory sites, these cytokines could not be detected in areas where oat cells were present. Thus, it is thought that other structures, such as the bronchus and bronchioles, rather than leukocytes, play a role in the release of these cytokines. The severity and distribution of COX-2, HMGB-1 and CD68 expression did not change in FBPN cases in which both Mannhemia and other bacterial agents, such as Pasteurella and Mycoplasma, were involved. This suggests that the release of these cytokines is not dependent on the causative agent, and they can be released in all cases of FBPN.

In conclusion, the cytokines COX-2, HMGB-1 and CD68 were compared for the first time by immunohistochemical methods in FBPNs in sheep. These cytokines are thought to play a role in the pathogenesis of FBPNs in sheep. COX-2 was shown to be released from inflammatory cell infiltrations, as well as bronchiolar and bronchial epithelia. On the other hand, HMGB-1 was expressed from the epithelia of the bronchi and glands. The increased COX-2 and HMGB-1 expression suggests that these cytokines could be used in the diagnosis of the disease. Further studies are necessary to determine which pathways are used in the expression of COX-2, HMGB-1 and CD68 in FBPNs in sheep.

\section{References}

1. Achouiti A., van der Meer A. J., Florquin S., Yang H., Tracey K. J., van't $\operatorname{Veer} C$., de $\operatorname{Vos} A$. F., van der Poll T.: High-mobility group box 1 and the receptor for advanced glycation end products contribute to lung injury during Staphylococcus aureus pneumonia. Crit. Care. 2013, 17, R296, doi: 10.1186/ cc13162.
2. Ackermann M. R., Brogden K. A.: Response of the ruminant respiratory tract to Mannheimia (Pasteurella) haemolytica. Microbes Infect. 2000, 2, 9, 1079-1088, doi: 10.1016/S1286-4579(00)01262-4.

3. Bemani E., EsmaeilzadefS., Gharibi D., Ghorbanpoor M.: Immunohistochemical and bacteriological investigations of Mannheimia haemolytica in sheep bronchopneumonia, Kafkas Univ. Vet. Fak. Derg. 2017, 23, 1, 7-14, doi: 10.9775/ kvfd.2016.15679.

4. Che D., Zhang S., Jing Z., Shang L., Jin S., Liu F., Shen J., Li Y., Hu J., Meng Q., $Y u$ Y: Macrophages induce EMT to promote invasion of lung cancer cells through the IL-6-mediated COX-2/PGE2/ $\beta$-catenin signaling pathway. Mol. Immunol. 2017, 90, 197-210, doi: 10.1016/j.molimm.2017.06.018.

5. Cho W. S., Chae C.: Expression of cyclooxygenase-2 in swine naturally infected with actinobacillus pleuropneumoniae. Vet. Pathol. 2003, 40, 1, 25-31, doi: 10.1354/vp.40-1-25.

6. Çiftçi M. K., Ortatatlı M., Erer H., Hatipoğlu F., Özdemir Ö. (ed.): Veteriner sistemik patoloji. $1^{\text {st }}$ ed., SÜ Basımevi, Konya 2015, p. 159-170.

7. Çiftçi M. K., Özdemir Ö., Yavuz O., Hatiopğlu F., Ortatatll M.: Routine activity results of department of pathology in faculty of veterinary medicine, Selcuk University: an overview in the first six months of 2012. VI. National Congress of Pathology with International Attendance, Bursa, Turkey 2012, p. 29.

8.Dă̆ S., Gürbüz A., Özen H., Büyük F., Çelebi Ö., Karaman M., Çitil M., Karakurt E.: Immunohistochemical and molecular detection of Mannheimia spp. and Pasteurella spp. in sheep with pneumonia in Kars province/Turkey. Kafkas Univ. Vet. Fak. Derg. 2018, 24, 281-288, doi: 10.9775/kvfd.2017. 18840.

9. Dincel G. C.: First description of enhanced expression of glia maturation factor-beta in experimental toxoplasmic encephalitis. J. Int. Med. Res. 2017, 45, 1670-1679 doi: 10.1177/0300060517700320.

10. Ding Y., Chu C., Li Y., Li G., Lei X., Zhou W., Chen Z.: High expression of HMGB1 in children with refractory Mycoplasma pneumoniae pneumonia. BMC Infect. Dis. 2018, 18, 439, doi: 10.1186/s12879-018-3346-8.

11. Hamada N., Maeyama T., Kawaguchi T., Yoshimi M., Fukumoto J., Yamada M., Yamada S., Kuwano K., Nakanishi Y.: The role of high mobility group box1 in pulmonary fibrosis. Am. J. Respir. Cell Mol. Biol. 2008, 39, 440-447, doi: 10.1165/rcmb.2007-0330OC.

12.Herceg M., Thurley D. C., Davies D. H.: Oat cells in the pathology of ovine pneumonia-pleurisy. N. Z. Vet. J. 1982, 30, 170-173, doi: 10.1080/ 00480169.1982 .34931

13. Ito Y., Torii Y., Ohta R., Imai M., Hara S., Kawano Y., Matsubayashi T., Inui A., Yoshikawa T., Nishimura N., Ozaki T., Morishima T., Kimura H.: Increased levels of cytokines and high-mobility group box 1 are associated with the development of severe pneumonia, but not acute encephalopathy, in 2009 H1N1 influenza-infected children. Cytokine. 2011, 56, 180-187, doi: 10.1016/ j.cyto.2011.07.016

14. Jeyaseelan S., Sreevatsan S., Maheswaran S. K.: Role of Mannheimia haemolytica leukotoxin in the pathogenesis of bovine pneumonic Pasteurellosis. Anim. Health Res. Rev. 2002, 3, 69-82, doi: 10.1079/AHRR200242.

15. Kang R., Chen R., Zhang Q., Hou W., Wu S., Cao L., Huang J., Yu Y., Fan X. G., Yan Z., Sun X., Wang H., Wang Q., Tsung A., Billiar T. R., Zeh H. J., Lotze M. T., Tang D.: HMGB1 in health and disease. Mol. Aspects M. 2014, 40, 1-116, doi: 10.1016/j.mam.2014.05.001.

16. Kılıç A., Kalender H., Eröksüz H., Muz A., Taşdemir B.: Identification by culture, PCR, and immunohistochemistry of mycoplasmas and their molecular typing in sheep and lamb lungs with pneumonia in Eastern Turkey. Trop. Anim. Health Prod. 2013, 45, 1525-1531, doi: 10.1007/s11250-013-0394-3.

17. Kim J., Lee S., Jeoung D., Kim Y. M., Choe J.: Activated human B cells stimulate COX-2 expression in follicular dendritic cell-like cells via TNF- $\alpha$. Mol. Immunol. 2018, 94, 1-6 doi: 10.1016/j.molimm.2017.12.004.

18. Kunisch E., Fuhrmann R., Roth A., Winter R., Lungershausen W., Kinne $R$. W.: Macrophage specificity of three anti-CD68 monoclonal antibodies (KP1, EBM11, and PGM1) widely used for immunohistochemistry and flow cytometry. Ann. Rheum. Dis. 2004, 63, 774-784 doi: 10.1136/ard.2003.013029.

19. Lappi-Blanco E., Kaarteenaho-Wiik R., Maasilta P. K., Anttila S., Pääkkö P., Wolff H. J.: COX-2 is widely expressed in metaplastic epithelium in pulmonary fibrous disorders. Am. J. Clin. Pathol. 2006, 126, 717-724 doi: 10.1309/ PFGX-CLNG-2N17-PJX9.

20.Lee I. T., Lin C. C., Lin W. N., Wu W. L., Hsiao L. D., Yang C. M.: Lung inflammation caused by adenosine-5'-triphosphate is mediated via $\mathrm{Ca} 2+1$ PKCs-dependent COX-2/PGE2 induction. Int. J. Biochem. Cell Biol. 2013, 45, 1657-1668, doi: 10.1016/j.biocel.2013.05.006.

21. Lopez A., Martinson S. A.: Respiratory system, mediastinum, and pleurae, [in:] Zachary J. F. (ed.): Pathologic basis of veterinary disease. $8^{\text {th }}$ edition, China: Elsevier 2017, p. 471-560. 
22. Lotze M. T., Tracey K. J.: High-mobility group box 1 protein (hmgb1): nuclear weapon in the immune arsenal. Nat. Rev. Immunol. 2005, 5, 331-342, doi: $10.1038 /$ nri1594.

23. Lutz W., Stetkiewicz J.: High mobility group box 1 protein as a late-acting mediator of acute lung inflammation. Int. J. Occup. Med. Environ. Health. 2004, 17, 245-254

24. Oruç E.: The pathologic and bacteriologic comparison of pneumonia in lambs. Turk. J. Vet. Anim. Sci. 2006, 30, 593-599.

25. Ozylldız Z., Tel O. Y., Yllmaz R., Özsoy S. Y., Keskin O.: Pathological and microbiological investigations of pneumonic pasteurellosis in sheep. Kafkas Univ. Vet. Fak. Derg. 2013, 19, 103-108, doi: 10.9775/kvfd.2012.7281.

26. Rice J. A., Carrasco-Medina L., Hodgins D. C., Shewen P. E.: Mannheimia haemolytica and bovine respiratory disease. Anim. Health Res. Rev. 2007, 8 , 2, 117-128, doi: 10.1017/S1466252307001375.

27. Sheehan M., Cassidy J. P., Brady J., Ball H., Doherty M. L., Quinn P. J., Nicholas R. A. J., Markey. B. K.: An aetiopathological study of chronic bronchopneumonia in lambs in Ireland. Vet. J. 2007, 173, 630-637, doi: 10.1016/ j.tvj1.2006.01.013.
28. Szymanski K. V., Toennies M., Becher A., Fatykhova D., N'Guessan P. D., Gutbier B., Klauschen F., Neuschaefer-Rube F., Schneider P., Rueckert J., Neudecker J., Bauer T. T., Dalhoff K., Drömann D., Gruber A. D., Kershaw O., Temmesfeld-Wollbrueck B., Suttorp N., Hippenstiel S., Hocke A. C.: Streptococcus pneumoniae-induced regulation of cyclooxygenase-2 in human lung tissue. Eur. Respir. J. 2012, 40, 1458-1467, doi: 10.1183/09031936.00186911.

29. Wang H., Bloom O., Zhang M., Vishnubhakat J. M., Ombrellino M., Che J., Frazier A., Yang H., Ivanova S., Borovikova L., Manogue K. R., Faist E., Abraham E., Andersson J., Andersson U., Molina P. E., Abumrad N. N., Sama A., Tracey K. J.: HMG-1 as a late mediator of endotoxin lethality in mice. Science 1999, 285, 248-251, doi: 10.1126/science.285.5425.248.

30. Yener Z., Ilhan F., Ilhan Z., Saglam Y. S.: Immunohistochemical detection of Mannheimia (Pasteurella) haemolytica antigens in goats with natural pneumonia. Vet. Res. Commun. 2009, 33, 305-313, doi: 10.1007/s11259-008-9178-z.

Corresponding author: Orhan Yavuz, DVM, PhD, Assit. Prof. Dr., Aksaray University, Faculty of Veterinary Medicine, Department of Pathology, 68100, Aksaray, Turkey; e-mail: vetorhanyavuz@gmail.com 